\author{
А.А. Гризо, І.М. Невмержицький, О.М. Додух, С.В. Сапегін \\ Харківський національний університет Повітряних Сил ім. І. Кожедуба, Харків
}

\title{
ПРОПОЗИЦІЇ ЩОДО МОДЕРНІЗАЦІЇ ПРИСТРОЮ ЗАХИСТУ ВІД АКТИВНИХ ШУМОВИХ ПЕРЕШКОД РЛС П-18 МАЛАХІТ
}

\begin{abstract}
Стаття присвячена проблемі захисту модернізованої РЛС П-18 Малахіт від активних иумових перешкод. Актуальність статті обумовлена тим, щчо в ичілях ефективного подолання системи ППО і подальшого нанесення ударів по важливим об 'єктам противник буде вести радіоелектронну боротьбу, невід'ємною частиною якої є радіоелектронне придушення радіоелектронних засобів системи протиповітряної оборони. В даний час на озброєнні радіотехнічних військ знаходиться сучасна РЛС П-18 Малахіт, метрового діапазону хвиль, щуо відноситься до станції чергового режиму, але за своїми точнісними характеристиками (за площинними координатами) наближається до РЛС бойового режиму. Фактично, за умови відсутності прийнятої на озброєння сучасної трикоординатної РЛС метрового (дециметрового) діапазону хвиль, зараз до РЛС П-18 Малахіт висувається вимога забезпечити видачу інформації з якістю, наближеною до бойової (за площинними координатами) в умовах дій активних шумових перешкод. У статті надані пропозииії щзодо варіанту модернізації комплекту автокомпенсатора перешкод АКАП4-02. Пропонується, за умови включення пристрою до складу РЛС у якості ї̈ системи виконувати операції придушення активних шумових перешкод у цифрровій формі, в якості автокомпенсатора перешкод доцільно використати автокомпенсатор $з$ прямим обчисленням керуючого коефіцієнту. Ефективність запропонованих рішень підтверджено шляхом імітаційного моделювання.
\end{abstract}

Ключові слова: шумова перешкода, перешкодозахист, автокомпенсатор перешкод.

\section{Вступ}

Досвід останніх військових конфліктів, у яких активно використовувалася авіаційна компонента, свідчить про те, що протиборчі сторони активно використовують сучасні комплекси радіоелектронної боротьби (РЕБ) для придушення системи протиповітряної оборони [1-2]. За поглядами експертів провідних країн світу використання засобів РЕБ дозволяє підвищити бойовий потенціал угруповання військ майже вдвічі і знизити втрати авіації майже вшестеро. Очікується, що гонка озброєнь у галузі радіоелектронної боротьби упродовж майбутніх років буде лише посилюватися [2-4].

Сучасний стан справ такий, що 3С промислово розвинутих країн світу мають та активно використовують можливості придушення радіоелектронних засобів (РЕЗ) зі складу системи ППО за допомогою різноманітних пілотованих та безпілотних літальних апаратів, вертольотів усіх видів, авіаційних засобів, які обладнані комплексами радіоелектронного придушення, що складаються з пристроїв постановки активних і пасивних перешкод [3].

На теперішній час на озброєнні радіотехнічних військ перебуває достатньо велика кількість сучасних РЛС П-18 “Малахіт” з цифровою обробкою сигналів, метрового діапазону хвиль [5-6]. Вони відносяться до станцій чергового режиму, але за своїми точнісними характеристиками (зокрема, за площинними координатами) наближаються до РЛС бойового режиму.

Фактично, за умови відсутності прийнятої на озброєння сучасної трикоординатної РЛС метрового (дециметрового) діапазону хвиль зараз до РЛС П-18 Малахіт висувається вимога забезпечити видачу інформації 3 якістю наближеною до бойової (за площинними координатами) в умовах дій активних шумових перешкод (АШЗ), що й обумовлює актуальність теми статті.

Постановка проблеми. У РЛС П-18 “Малахіт” використовується автокомпенсатор перешкод (АКЗ), що реалізовано у вигляді окремого блоку АКАП4-02 та додаткових антен. Слід зазначити, що розробка комплекту АКАП4-02 виконувалася стороннім виробником, і у складі РЛС він постачається як опція, це спричинило певні особливості його побудови, зокрема пристрій $є$ аналоговим, хоча подальша обробка виконується у цифровій формі.

3 метою покращення якості компенсації активних шумових перешкод пропонується модифікація комплекту АКАП4-02. За умови включення пристрою до складу РЛС у якості iї системи пропонується виконувати операції придушення активних шумових перешкод у цифровій формі. У якості АКЗ доцільно використати АКЗ з прямим обчисленням керуючого коефіцієнту. Наголошується, що він про- 
стіше реалізується у цифровій формі, має менший час настроювання та, потенційно, дозволяє реалізувати краще відношення сигнал/перешкода на виході AK3 $[10 ; 13]$.

Аналіз останніх досліджень та публікацій. Методи захисту РЛС від активних шумових перешкод поділяються на адаптивні та неадаптивні [7]. У наземних оглядових РЛС більшого розповсюдження набули адаптивні методи захисту, це обумовлено мінливим характером сигнально перешкодової обстановки при веденні огляду повітряного простору [8-9]. Адаптивні методи захисту передбачають ускладнення структури РЛС у зв'язку з необхідністю введення додаткових компенсаційних каналів прийому та адаптивних пристроїв компенсації перешкод [9-10]. До таких пристроїв можливо віднести АКЗ різних варіантів побудови або адаптивні антенні решітки $[7 ; 11]$.

Традиційно у РЛС РТВ компенсація АШЗ виконується 3 використанням АКЗ [10; 12-13]. Ідея компенсації АШЗ в таких пристроях полягає у наступному. Крім основного приймача, якій обробляє суміш перешкоди і корисного сигналу, використовується додатковий (компенсаційний) приймач, антена якого сприймає переважно перешкоди. Мета амплітудно-фазової обробки сигналів перешкод при такому методі компенсації полягає в тому, щоб забезпечити отримання однакових за інтенсивністю i протилежних за фазою сигналів перешкод в основному і компенсаційному приймачах. Компенсація здійснюється шляхом віднімання сигналів перешкод додаткового каналу з сигналів перешкод основного каналу. При цьому перешкода компенсується, а сигнал залишається неспотвореним [12].

Метою статті $\epsilon$ розробка рекомендацій щодо удосконалення системи захисту від перешкод РЛС П-18 Малахіт.

\section{Виклад основного матеріалу}

У РЛС П-18 Малахіт використовується АКЗ, що реалізовано у вигляді окремого блоку АКАП4-02, який реалізує відому схему АКЗ 3 кореляційним зворотнім зв'язком.

Як відомо, робота такого компенсатора описується системою рівнянь [12]:

$$
\begin{gathered}
\dot{U}_{\Sigma}(t)=\dot{U}_{0}(t)+\dot{K}(t) \dot{U}_{1}(t), \\
T \frac{d \dot{K}(t)}{d t}+\dot{K}(t)=-\gamma \dot{U}_{\Sigma}(t) \dot{U}_{1}^{*}(t),
\end{gathered}
$$

де $\dot{U}_{0}(t), \dot{U}_{1}(t), \dot{U}_{\Sigma}(t)$ - комплексні обвідні процесів відповідно на вході основного і допоміжного каналів та на виході автокомпенсатора;

$\dot{K}(t)$ - комплексна величина керуючого (ваго- вого) коефіцієнта;

$T$ - постійна часу інтегрування;

$\gamma$ - коефіцієнт підсилення напруги в колі зворотного зв'язку;

“*” - знак комплексного спряження.

В усталеному режимі величина керуючого коефіцієнта

$$
\dot{K}=-\gamma \overline{\dot{U}_{\Sigma}(t) \dot{U}_{1}^{*}(t)}
$$

де “-_" - знак математичного усереднення у часі.

Таким чином, керуючий коефіцієнт (3) визначається як кореляція процесів, які діють на вході допоміжного каналу та на виході автокомпенсатора. Тому пристрій, який формує цей коефіцієнт, називається корелятором, а весь автокомпенсатор - кореляційним.

Якщо співвідношення (1) підставити до (3) та обирати коефіцієнт підсилення в колі зворотного зв'язку $\gamma$ таким, що $\gamma \overline{\dot{U}_{1}(t) \dot{U}_{1}^{*}(t)}>>1$, отримаємо кінцевий вираз для керуючого коефіцієнта:

$$
\dot{K}=-\frac{\overline{\dot{U}_{0}(t) \dot{U}_{1}^{*}(t)}}{\overline{\dot{U}_{1}(t) \dot{U}_{1}^{*}(t)}} .
$$

Алгоритм роботи автокомпенсатора за виразом (4) називають алгоритмом с прямим обчисленням вагових коефіцієнтів (керуючого коефіцієнту).

Прилад компенсації перешкод АКАП4-02 являє собою чотирьохканальний АКЗ з кореляційним зворотнім зв'язком квадратурного типу. Всі чотири канали АКЗ ідентичні по складу і характеристикам елементів, вагові коефіцієнти обчислюються за виразом (3). Структурна схема приладу компенсації перешкод АКАП4-02 наведена на рис. 1.

Кожен додатковий канал розбитий на два підканали, які обробляють квадратурні складові перешкод компенсаційного каналу. Це обумовлено необхідністю формування протифазної напруги перешкоди в компенсаційному каналі для іiї компенсації при довільних міжканальних фазових зрушеннях. Процес компенсації перешкоди полягає в мінімізації дисперсії перешкоди на виході суматора шляхом формування відповідних коефіцієнтів передачі для кожного 3 квадратури підканалів компенсаційного каналу.

АКЗ своїм основним каналом вмикається в розрив кола між виходом підсилювача високої частоти ПВЧ та входом решти частини приймача РЛС. Входами АКЗ є вихід ПВЧ та виходи чотирьох компенсаційних антен. Виходом АКЗ є вихід суматора. АКЗ $є$ пристроєм автоматичного регулювання с кореляційними зворотними зв'язками, якими охоплені всі чотири канали. 


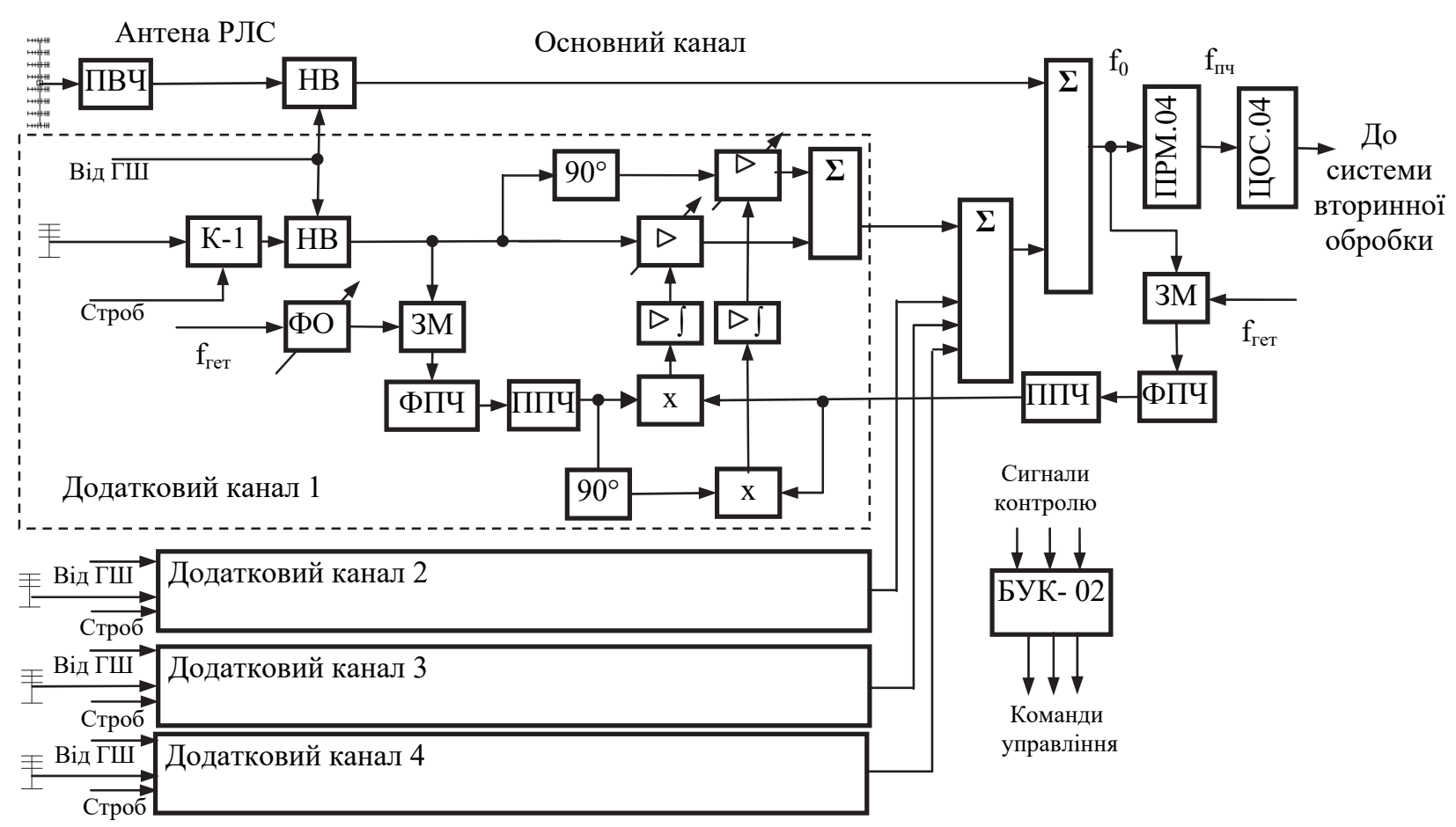

Рис. 1. Структурна схема приладу компенсації перешкод АКАП4-02

Джерело: розроблено авторами за даними $[14$, С. 6].

Кореляційний зворотний зв'язок в кожному каналі утворюється шляхом перемноження перешкодових сигналів на вході та виході автокомпенсатора та наступного інтегрування результату перемноження у підсилювачі-інтеграторі. Напруга, що виникає при цьому, керує коефіцієнтами передачі каналів так, щоб при додаванні виходів всіх каналів потужність зовнішньої перешкоди була мінімальною.

На входах кожного каналу компенсації включені високочастотні комутатори К 1 - К4, призначені для захисту вхідних кіл (підсилювачів) каналів від потужних зондуючих сигналів РЛС. Комутатори керуються імпульсами стробу, що поступають від синхронізатора РЛС та співпадають 3 моментами випромінювання зондуючих сигналів РЛС. 3 надходженням цих імпульсів входи підсилювачів замикаються на корпус. Перемноження сигналів в колі зворотного зв'язку здійснюється на частоті, що дорівнює проміжній частоті приймача РЛС. Для цього перешкодові сигнали з виходу суматора та входів каналів подаються на змішувачі 3М, на інші входи яких через керуючі фазообертачі надходить напруга від гетеродина приймача РЛС.

В фільтрах проміжної частоти ФПЧ виділяється перешкода на проміжній частоті та підсилюється в ППЧ. Перед перемноженням перешкода розділяється на дві гілки. В одній з них фаза перешкодового сигналу залишається без змін, в іншій фаза змінюється на $90^{\circ}$. Таким чином формуються два квадратурних канали зворотного зв'язку.

Так само в прямій гілці компенсаційного каналу створюються два квадратурних канали, в кожно- му з яких включені елементи з регульованим коефіцієнтами передачі. Результати перемноження перешкодових сигналів проходять через підсилювачіінтегратори. При цьому утворюються дві напруги, що повільно змінюються. Вони подаються на керуючі входи підсилювачів-регуляторів та виконують роль регулюючих напруг. В залежності від величини та знаку регулюючої напруги їх коефіцієнт передачі може змінитися в межах від -1 до +1 . Незалежне регулювання коефіцієнта передачі двох квадратурних каналів приводить до зміни величини модуля коефіцієнта передачі та зсуву фаз перешкодового сигналу в кожному каналі компенсації. При правильній настройці каналів перешкоди на виходах суматора приблизно рівні за величиною і протилежні за фазою. Таким чином забезпечується компенсація перешкоди в каналі РЛС.

Умовою правильної настройки блоку компенсації $є$ ідентичність фазових зсувів перешкодових сигналів, що поступають в колі зворотного зв'язку на входи перемножувала того квадратурного каналу, де відсутнє фазозсуваюче коло на $90^{\circ}$. Щоб виключити можливу неідентичність, передбачене регулювання фази перешкоди в колі зворотного зв'язку кожного каналу шляхом зміни фази гетеродинної напруги. Для цього напруга гетеродину приймача РЛС поступає на змішувачі в колах зворотного зв'язку через керуємі фазообертачі ФО. Регулювання цих фазообертачів здійснюється тільки на етапі підготовки приладу до роботи, забезпечуючи максимум коефіцієнта послаблення перешкоди.

Генератор шуму, що входить до складу прила- 
ду АКАП4-02 (на схемі не показано), призначений для контролю працездатності приладу та настройки компенсаційних каналів на максимальне послаблення перешкоди. Шумова напруга від ГШ може подаватися на вхід основного каналу та почергово в кожний компенсаційний канал через спрямовані відгалужувачі.

Блок керування та контролю (БУК-02) призначений для оперативного контролю працездатності приладу АКАП4-02 та управління його режимами роботи на етапі контролю. Блок дозволяє контролювати основні параметри АКЗ, що впливають на величину послаблення перешкод.

Остаточно сигнали, “очищені” від перешкод, надходять на плату приймача ПРМ.04, де зазнають підсилення та перетворення на проміжну частоту. Сигнали на проміжній частоті надходять на вхід пристрою ЦОС.04, якій виконує функції АЦП, внутрішньо та міжперіодної обробки.

3 метою покращення якості компенсації активних шумових перешкод пропонується наступна модифікація комплекту АКАП4-02.
Слід зазначити, що розробка комплекту АКАП4-02 виконувалася стороннім виробником і у складі РЛС він постачається опціонально, це спричинило певні особливості його побудови, зокрема пристрій $є$ аналоговим, хоча подальша обробка виконується у цифровій формі. Крім того, кореляційні зворотні зв'язки працюють на проміжній частоті, для чого проводиться відповідне перетворення у кожному каналі, а компенсація перешкоди відбувається на робочій частоті РЛС.

Пропонується, за умови включення пристрою до складу РЛС у якості ії системи виконувати операції придушення АШЗ у цифровій формі, в якості АКЗ доцільно використати АКЗ з прямим обчисленням керуючого коефіцієнту (4). У [10] наголошується, що він має менший час настроювання, та потенційно дозволяє реалізувати краще відношення сигнал/перешкода на виході АКЗ. Структурна схема модифікованого приладу компенсації перешкод РЛС П-18 Малахіт наведена на рис. 2.

Пропонується ввести до складу додаткових каналів плати приймача ПРМ.04, пристрої АЦП та обробки ЦОС.04 зі складу основного каналу.

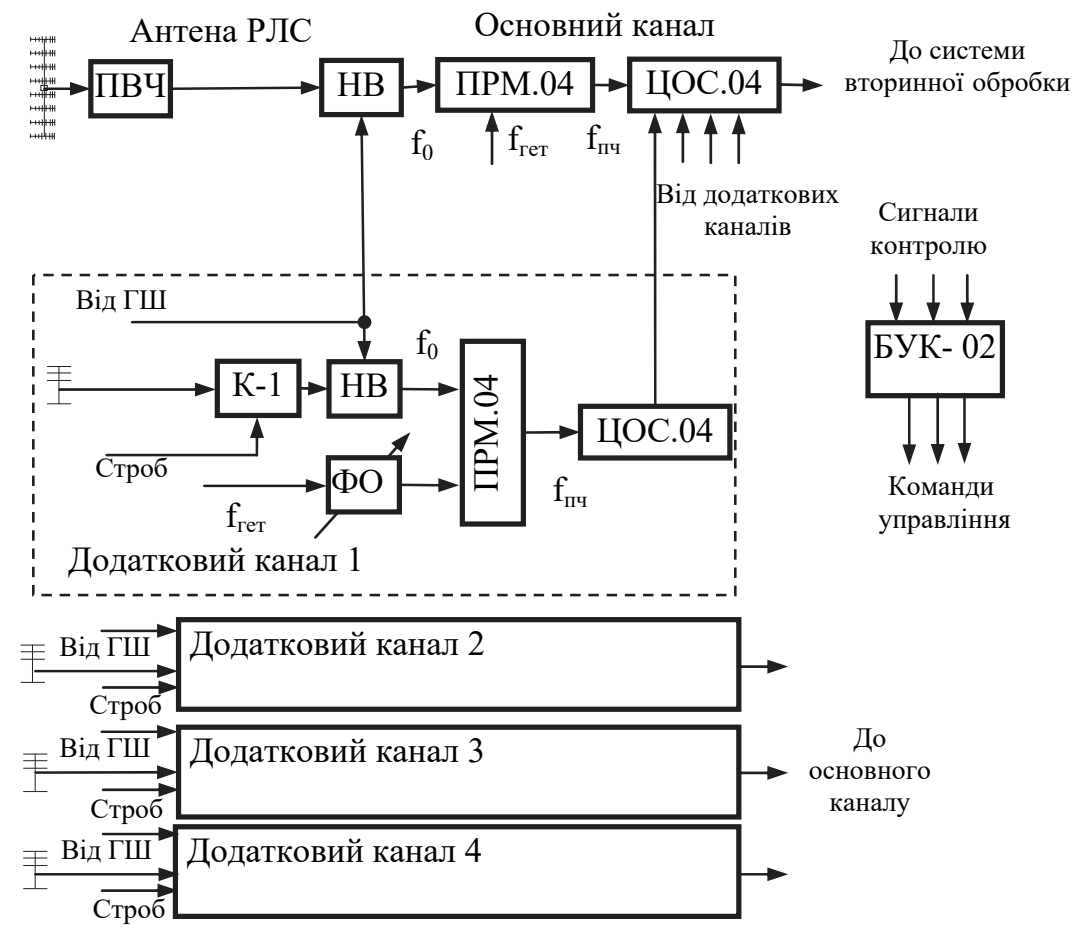

Рис. 2. Структурна схема модифікованого приладу компенсації активних шумових перешкод Джерело: розроблено авторами.

Прийняті коливання основного та додаткових каналів надходять на однакові приймальні пристрої ПРМ.04, де зазнають підсилення та перетворюються на проміжну частоту.

Далі сигнали надходять на пристрої ЦОС.04, які перетворюють сигнали у цифрову форму, відмінність пристрою ЦОС.04 полягає у наявності ци- фрових входів від додаткових каналів. Пристрій ЦОС.04 містить у своєму складі дві ПЛІС та пристрій їх програмування. Пропонується реалізувати потрібні алгоритми обробки шляхом їх перепрограмування.

Такий підхід дозволяє максимально уніфікувати пристрої обробки, крім того, цифрова реалізація 
операцій АКЗ на теперішній час буде коштувати дешевше, ніж реалізація за допомогою аналогових НВЧ пристроїв. Крім того, АКЗ з прямим обчисленням вагових коефіцієнтів має переваги у порівнянні зі схемою $з$ кореляційним зворотнім зв'язком. Він має більш високу стійкість та швидкодію. Можна вважати, що АКЗ с прямим обчисленням вагових коефіцієнтів більш доцільно використовувати при цифровій реалізації.

3 метою перевірки працездатності запропонованого варіанту модернізації проведено імітаційне моделювання. На рис. 3 наведено процеси на вході основного та додаткового каналів для випадку співвідношення амплітуд 1/2. По осі абсцис відкладено номер відліку, а по осі ординат - амплітуда. Суцільною лінію зображено сигнали у основному каналі (перевищують рівень власних шумів у 30 разів), точковою - у додатковому (перевищують рівень власних шумів у 60 разів), у основному каналі присутній сигнал цілі.

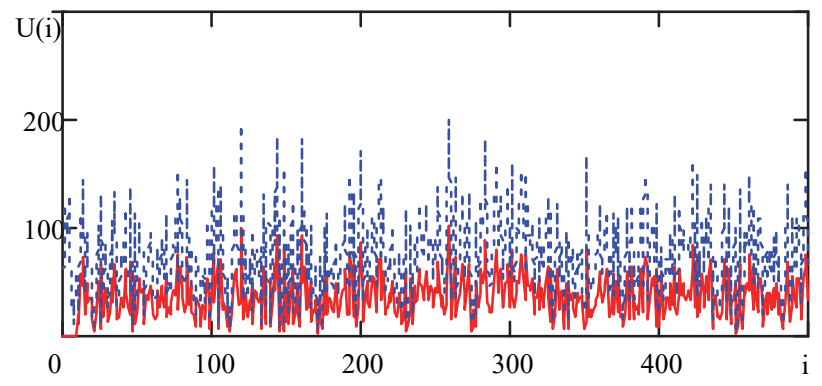

Рис. 3. Реалізації сигналів на вході АКЗ Джерело: розроблено авторами.

Вважаємо, що аналого-цифрове перетворення у каналах виконується за теоремою Котельнікова, тобто на протязі тривалості ехо-сигналу береться, принаймні, три відліки сигналу, розподіленого за нормальним законом, його потужність, яка перевищує рівень власних шумів у 20 разів. Така потужність відповідає потужності ехо-сигналу від цілі на дальній межі зони виявлення (відношення сигнал/шум 13 дБ, умовна вірогідність правильного виявлення $D=0.5$, умовна вірогідність хибної тривоги $F=10^{-6}$ ).

На рис. 4 зображено процес на виході АКЗ 3 кореляційним зворотнім зв'язком, шумова перешкода придушена, на початку дистанції спостерігається процес настроювання АКЗ, починаючи з 100 відліка спостерігається сигнал цілі. Швидкодія АКЗ обрана таким чином, щоби час настроювання був утричі більший ніж тривалість корисного сигналу (10 відліків).

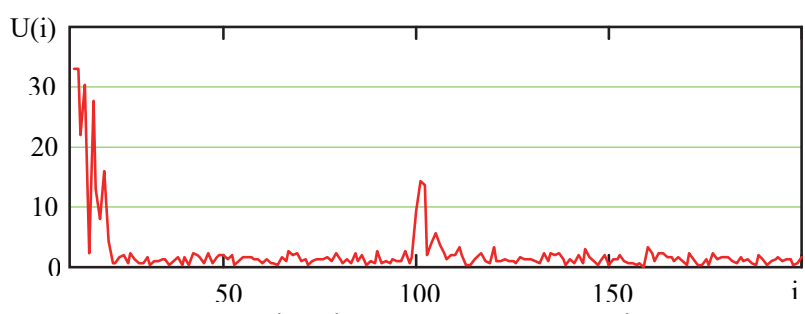

Рис. 4. Реалізація сигналу на виході АКЗ

3 кореляційним зворотнім зв'язком Джерело: розроблено авторами.

На рис. 5 зображено процес на виході АКЗ 3 прямим обчисленням вагових коефіцієнтів, шумова перешкода придушена, процес настроювання АКЗ майже вдвічі менший, сигнал цілі має більшу величину відносно рівня залишків перешкоди.

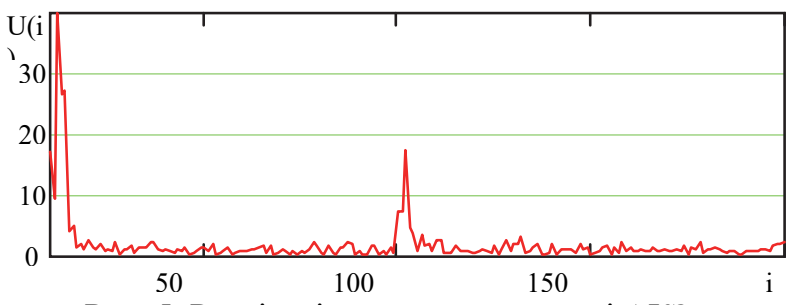

Рис. 5. Реалізація сигналу на виході АКЗ

3 прямим обчисленням вагових коефіцієнтів Джерело: розроблено авторами.

Проведені розрахунки показують, що покращення відношення сигнал/перешкода становить приблизно 2 дБ у порівнянні з АКЗ з кореляційним зворотнім зв'язком. Настроювання АКЗ з прямим обчисленням вагових коефіцієнтів відбувається на $25 \%$ скоріше ніж АКЗ з кореляційним зворотнім зв'язком при співвідношенні амплітуд в каналах 1:2.

\section{Висновки}

3 метою покращення якості компенсації активних шумових перешкод у РЛС П-18 Малахіт пропонується, за умови включення пристрою АКАП4-02 до складу РЛС у якості їі системи, виконувати операції придушення активних шумових перешкод у цифровій формі, в якості АКЗ доцільно використати АКЗ з прямим обчисленням керуючого коефіцієнту. Він має менший час настроювання та потенційно дозволяє реалізувати краще відношення сигнал/перешкода на виході АКЗ. Крім того, за рахунок реалізації його у цифровій формі коефіцієнт придушення додатково збільшиться.

Ефективність запропонованого варіанту модернізації пристрою АКЗ РЛС П-18 “МАЛАХІТ” підтверджена шляхом імітаційного моделювання.

\section{Список літератури}

1. John D. Murphy. An Analysis of the United States-Led Coalition Air Campaign Conducted During the 1991 War with IRAQ: Desert Storm, Report published 1 Jan 2002. [Електронний ресурс]. - Режим доступу: https://doi.org/10.21236/ada401042. 
2. Сучасне озброєння і військова техніка Збройних сил Російської Федерації. Довідник учасника ООС / С.П. Корнійчук, О.В. Туринський, Г.В. Пєвцов, та ін.; за заг. ред. С.П. Корнійчука. - Х.: ДІСА ПЛЮС, 2020. - 1220 с.

3. Камалтинов Г.Г. Тенденції розвитку радіолокаційних засобів контролю повітряного простору / Г.Г. Камалтинов, О.М. Колеснік // Збірник наукових праць Харківського національного університету Повітряних Сил. - 2020. № 2(64). - C. 89-95. https://doi.org/10.30748/zhups.2020.64.13.

4. Напрямки розвитку радіолокаційних засобів розвідки та контролю повітряного простору / О.В. Бєлавін, В.Й. Климченко, Г.Г. Камалтинов, О.С. Маляренко // Збірник наукових праць Харківського національного університету Повітряних Сил. - 2014. - № 3(40). - С. 47-52.

5. Офіціальний сайт UST.COM.UА. РЛС “МАЛАХИТ” Компанія АТ “ХК”. - Режим доступу: http://ust.com.ua/uk/ item/rls-malaxit-2/.

6. Пропозиції щодо використання багаточастотного зондуючого сигналу для підвищення якості завадозахисту модернізованих РЛС П-18МА та П-18 Малахіт / А.А. Гризо, О.О. Альчаков, І.М. Лашкул, В.А. Полтавець // Наука і техніка Повітряних Сил Збройних Сил України. - 2019. - № 2(35). - С. 143-150. https://doi.org/10.30748/nitps.2019.35.18.

7. Monzingo Robert A. Introduction to Adaptive Arrays; 2nd ed. / Robert A. Monzingo, Randy L. Haupt, Thomas W. Miller. - SciTech Publishing, Inc. Raleigh, NC 27615, 2011. - 686 p. https://doi.org/10.1049/SBEW046E.

8. Atamanskyi D. Advanced network of radar aids to aviation meteorological services / D. Atamanskyi // Scientific Works of Kharkiv National Air Force University. 2018. Vol. 3 (57). P. 92 - 103. https://doi.org/10.30748/zhups.2018.57.14.

9. Xu Jingwei. Space-time-range adaptive processing for airbon radar systems / Jingwei Xu, Shengqi Zhu, Guisheng Liao // IEEE Sensors J. - Mar 2015. - Vol. 15. - No. 3. -P. 1602-1610. https://doi.org/10.1109/JSEN.2014.2364594.

10. Пиза Д.М. Метод компенсации активной составляющей комбинированной помехи в когерентно-импульсных РЛС / Д.М. Пиза, Е.А. Звягинцев, Г.В. Мороз // Известия вузов. Радиоэлектроника. - 2016. - Т. 59. - № 6. - С. 23-29. https://doi.org/10.20535/S0021347016060030.

11. Защита когерентно-импульсных РЛС от комбинированных помех. 1. Разновидности систем ПВОС и их предельные возможности / Д.И. Леховицкий, В.П. Рябуха, А.В. Семеняка, Д.В. Атаманский, Е.А. Катюшин // Известия вузов. Радиоэлектроника. - 2019. - Т. 62. - № 7. - С. 380-412. https://doi.org/10.20535/S002134701907001X.

12. Радиоэлектронные системы: Основы построения и теория. Справочник. Изд. 2-е, перераб. и доп. / Под ред. Я.Д. Ширмана. - М.: Радиотехника, 2007. - 512 с.: ил.

13. Пат. 78120 Україна, МПК G01S 7/36 Спосіб захисту когерентно-імпульсних радіолокаційних станцій від комбінованих завад / Піза Д.М., Сіренко А.С.; Запорізький національний технічний університет; заявл. 28.08.2012; опубл. 11.03.2013, Бюл. № 5 .

14. Комплект АКАП4-02. Руководство по эксплуатации. АОФА.468164.08РЭ. - Х.: НИИ РЭТ, 2004. - 37 с.

\section{Відомості про авторів:}

\section{Гризо Андрій Аркадійович}

кандидат технічних наук доцент

доцент кафедри Харківського національного університету Повітряних Сил ім. І. Кожедуба, Харків, Україна

https://orcid.org/0000-0003-2483-5953

\section{Невмержицький Ігор Михайлович}

кандидат технічних наук доцент

доцент кафедри Харківського національного університету Повітряних Сил ім. І. Кожедуба, Харків, Україна

https://orcid.org/0000-0002-5499-6785

\section{Додух Олександр Миколайович}

кандидат технічних наук

викладач кафедри Харківського національного університету Повітряних Сил ім. І. Кожедуба, Харків, Україна

https://orcid.org/0000-0002-8884-9206

\section{Сапегін Свген Вікторович}

курсовий офіцер

Харківського національного університету

Повітряних Сил ім. І. Кожедуба,

Харків, Україна

https://orcid.org/0000-0003-3731-1008

\section{Information about the authors:}

\section{Andrii Hryzo}

Candidate of Technical Sciences Associate Professor

Senior Lecturer of Ivan Kozhedub

Kharkiv National Air Force University,

Kharkiv, Ukraine

https://orcid.org/0000-0003-2483-5953

\section{Igor Nevmerzhitsky}

Candidate of Technical Sciences Associate Professor

Senior Lecturer of Ivan Kozhedub

Kharkiv National Air Force University,

Kharkiv, Ukraine

https://orcid.org/0000-0002-5499-6785

\section{Oleksandr Dodukh}

Candidate of Technical Sciences

Instructor of Ivan Kozhedub

Kharkiv National Air Force University,

Kharkiv, Ukraine

https://orcid.org/0000-0002-8884-9206

\section{Yevhen Sapehin}

Course Officer

of Ivan Kozhedub Kharkiv

National Air Force University,

Kharkiv, Ukraine

https://orcid.org/0000-0003-3731-1008 


\section{ПРЕДЛОЖЕНИЯ ПО МОДЕРНИЗАЦИИ УСТРОЙСТВА ЗАЩИТЫ ОТ АКТИВНЫХ ШУМОВЫХ ПОМЕХ РЛС П-18 МАЛАХИТ}

\section{А.А. Грызо, И.М. Невмержицкий, А.Н. Додух, Е.В. Сапегин}

Статья посвящена проблеме защиты модернизированной РЛС П-18 Малахит от активных шумовых помех. Актуальность статьи обусловлена тем, что в целях эффективного преодоления системь ПВО и дальнейшего нанесения ударов по важным объектам противник будет вести радиоэлектронную борьбу, неотъемлемой частью которой является радиоэлектронное подавление радиоэлектронных средств системы противовоздушной обороны. $B$ настоящее время на вооружении радиотехнических войск находится современная РЛС П-18 Малахит, метрового диапазона волн, она относится к станциям дежурного режима, но по своим точностным характеристикам (по плоскостным координатам) приближается к РЛС боевого режима. Фактически, при отсутствии принятой на вооружение современной трехкоординатной РЛС метрового (дециметрового) диапазона волн, сейчас к РЛС П-18 Малахит выдвигается требование обеспечить выдачу информации с качеством приближенной к боевой (по плоскостными координатами) в условиях действий активных иумовых помех. В статье представлен вариант модернизации комплекта автокомпенсатора помех АКАП4-02. Предлагается, при условии включения устройства в состав РЛС в качестве ее системы, выполнять операции подавления активных шумовых помех в цифровой форме, в качестве автокомпенсатора помех целесообразно использовать автокомпенсатор с прямым вычислением управляющего коэффициента. Эффективность предложенных решений подтверждена путем имитачионного моделирования.

Ключевые слова: шумовая помеха, помехозащчта, автокомпенсатор помех.

\section{SUGGESTIONS FOR MODERNIZATION OF PROTECTION DEVICE OF RADAR П-18 MALAKHITE FROM ACTIVE NOISE INTERFERENCE}

\section{A. Hryzo, I. Nevmerzhitsky, O. Dodukh, Y. Sapehin}

The problem of protection of the modernized Malakhite P-18 radar against active noise interference has been considered. The challenge is of utmost significance and comes as a high-priority task. On planning a strike at important objects, the enemy would inevitably be seeking to overcome efficiently the adverse air defense system and would necessarily start electronic warfare, electronic suppression of electronic defense aids being its integral part. Currently, the radio engineering troops are provided with a modern Malakhite P-18 radar operating in a meter wave range. Being classified as a duty-type scanning (survey) station, the radar is distinguished for its high accuracy characteristic (within plane coordinates), which brings it closer to combat systems. Since the modern three-coordinate meter/decimeter wave range radar is unavailable now, the Malakhite $P$ - 18 is expected to meet the requirements of military applications, i.e. to operate under active noise conditions and provide information of a quality level close to that of a combat system (in the plane coordinates), which has motivated the subject of this article.

Traditionally, the active noise interference in ground survey radars is compensated using autocompensators. The process of compensating of active noise interference is as follows. Along with the main receiver which processes an interference-useful signal mixture, an additional (compensating) receiver is used, whose antenna perceives mainly interference. Compensation is achieved by subtracting the noise signals received by the additional channel from the noise signals of the main channel. The interference is thus compensated and the resulting signal remains undistorted. Some propositions are advanced in this article as an option of upgrading the interference autocompensator AKAП4-02. It should be noted that the AKAП4-02 set was developed and constructed by a third-party manufacturer, who supplied it as an option for the radar. This brings about certain salient features of its construction. In particular, the device operates in the analog mode, however the further processing is performed in the digital mode. Besides, the correlation feedbacks operate at an intermediate frequency, which requires a special conversion procedure in each channel and interference compensation occurs at the operating frequency of the radar. It is proposed that the device should be built into the radar structure as its system component capable of performing ACS suppression operations in the digital mode. It is advisable to use an ACS affording direct calculation of the control factor. Note that this type of ACS has a shorter tuning time and the potential of a better signal-to-noise ratio at the ACC output. The efficiency of the proposals described in this article has been tested and confirmed through simulation procedures.

Keywords: noise interference, noise protection, autocopensator of disturbances. 